\title{
POSSÍVEIS INFLUÊNCIAS DO NOVO ENEM NOS CURRÍCULOS EDUCACIONAIS DE QUIIMICA
}

LEONARDO VICTOR MARCELINO MARIA CELINA PIAZZA RECENA

\section{RESUMO}

O Exame Nacional do Ensino Médio foi criado em 1998 e reformulado em 2009 para atender a novos objetivos, dos quais se destaca a reestruturação dos currículos do ensino médio. Foram analisados, com base na Taxonomia Revisada de Bloom, os objetivos educacionais referentes à Química ou Ciências descritos nas Habilidades e Competências da Matriz de Referência de Ciências da Natureza e suas Tecnologias do Enem 2009, atualmente válida. As dimensões do conhecimento e do processo cognitivo foram analisadas e classificadas em extensão e profundidade na Tabela Taxonômica e ficou demonstrado que a ênfase dos objetivos das competências é entender e aplicar conhecimentos procedimentais, enquanto que das habilidades é entender e lembrar conhecimentos conceituais. Conclui-se que o novo Enem pouco pode interferir no ensino tradicional, contribuindo para a formação de um indivíduo conformado com sua realidade e incapaz de pensar ativamente sobre ela ou propor meios de alterá-la. 


\section{RESUMEN}

El Examen Nacional de Enseñanza Media fue creado en 1998 y reformulado en 2009 para atender nuevos objetivos, de los cuales se destaca la reestructuración de los planes de estudio de enseñanza media. Se analizaron, con base en la Taxonomía Revisada de Bloom, los objetivos educativos referentes a química o ciencias, descriptos en las habilidades y competencias de la matriz de referencia de ciencias naturales y sus tecnologías del Enem 2009, actualmente válida. Las dimensiones del conocimiento y del proceso cognitivo se analizaron y clasificaron en extensión y profundidad en la Tabla Taxonómica. Se demostró que el énfasis de los objetivos de las competencias es entender y aplicar conocimientos procedimentales, mientras que el de las habilidades es entender y recordar conocimientos conceptuales. Se concluyó que el nuevo Enem puede interferir poco en la enseñanza tradicional, contribuyendo a la formación de un individuo conformado con su realidad, pero incapaz de pensar activamente sobre ella o proponer medios para alterarla.

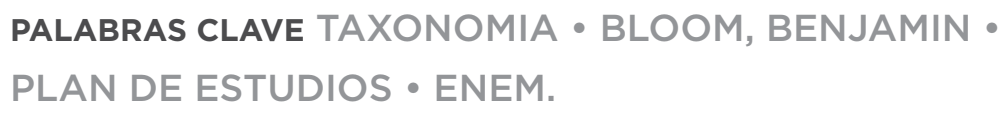

\section{ABSTRACT}

The National Examination of Secondary Education - Enem was established in 1998 and redesigned in 2009 to meet new goals, among which are the restructuring of the school syllabuses. Based on Bloom's Revised Taxonomy, we analyzed the educational goals relating to chemistry or science as described in Enem 2009's Skills and Competencies of the Reference Matrix for Natural Sciences and Technologies, currently in force. The dimensions of the Knowledge and Cognitive Process were analyzed and classified in breadth and depth in the Taxonomic Table and have shown that the emphasis of the Competencies goals is to Understand and Apply Procedural knowledge, while those of Skills are to Understand and Remember information. We conclude that little can change in traditional teaching, contributing to shaping an individual who accepts reality, is unable to actively think about it or propose ways to change it. 


\section{INTRODUÇÃO}

O Exame Nacional do Ensino Médio (Enem), criado em 1998 pela Portaria n. 438, de 28 de maio do mesmo ano (BRASIL, 1998a), objetivava funcionar como ferramenta voluntária de autoavaliação para alunos concluintes do ensino médio. Em 2009, por meio da Portaria n. 109 de 27 de maio (BRASIL, 2009b), art. 2º o MEC amplia os objetivos do exame, que passam a ser: (I) autoavaliação; (II) seleção para o mundo do trabalho; (III) seleção para continuidade nos estudos; (IV) meio de participação em programas governamentais; (V) certificação para jovens e adultos no nível de conclusão do ensino médio; avaliação de (VI) escolas e (VII) alunos.

Nota-se, principalmente em seus objetivos (VI e VII), a intenção do governo federal de interferir no ensino médio, pois indica que o Enem será o critério de avaliação do desempenho acadêmico das escolas e seus estudantes, o que fica mais exposto na página de divulgação do exame, que declara como principais objetivos: “democratizar as oportunidades de acesso às vagas federais de ensino superior, possibilitar a mobilidade acadêmica e induzir a reestruturação dos currículos do ensino médio" (BRASIL, 2011, grifo nosso). 
É justamente nesse objetivo que se fixa a atenção desta análise. Diversos autores (FREITAS et al., 2009; MACENO et al., 2011; MENDONÇA, 2010; MINHOTO, 2003; RAMALHO, NÚÑEZ, 2011; SOUSA, 2003) têm ressaltado as possibilidades de a prova concretizar as mudanças previstas em documentos oficiais: a formação de valores para o exercício da cidadania, a interdisciplinaridade e a contextualização como eixos estruturadores da formação de competências necessárias ao mercado de trabalho e ao entendimento crítico da realidade (BRASIL, 2000b, p. 92).

Fini (2005) e Macedo (2005), como citados por Gomes e Borges (2009, p. 75), defendem que o antigo Enem tem traços construtivistas, valorizando a capacidade do indivíduo de relacionar informações para resolver problemas. Assim, é necessário que ele saiba interpretar e organizar informações para projetar soluções inovadoras. Maceno et al. (2011) apontam que a nova matriz do exame preconiza a integração das disciplinas, a articulação do conhecimento científico com a tecnologia e a mobilização de informações diante de situações do cotidiano, considerando dimensões amplas e indo além da aprendizagem por memorização.

Gomes e Borges (2009, p. 80) encontraram como resultado de pesquisa que três habilidades juntas explicaram $60 \%$ da variância do desempenho dos estudantes analisados na prova do Enem 2001, que se relacionam a: resolução de problemas (52\%); rapidez cognitiva (5\%), que indica uso de processos coginitivos de velocidade de processamento em nível espacial, verbal, numérico, etc. e compreensão verbal (3\%). Entretanto, a análise foi feita com a prova de 2001, antes da reformulação do exame em 2009 que, para atender ao objetivo de seleção para as Instituições de Ensino Superior (IES), teve seu modelo diferenciado.

Maceno e colaboradores (2011, p. 154-157) encontram na atual matriz referencial do exame o enfoque na interdisciplinaridade, nas relações entre ciência e tecnologia, na contextualização e na valorização da linguagem como meio de construção do conhecimento, o que Ramalho e Núñez (2011) encontram na análise da prova de 2009. No entanto, a análise dos anexos da Matriz Referencial, os Objetos de Conhecimento - texto que traz listagem de conteúdos e currículos praticados nas escolas, elaborados por IES a pedido do MEC -, contradiz o exposto na referida matriz, ao pensar em atualização 
curricular como incorporação de novos tópicos de ensino a uma lista de conteúdos, como a apresentada no referido anexo, que segue uma ordem desvinculada da realidade da escola, contrariando a contextualização e até mesmo as relações entre ciência e tecnologia, que adquiririam caráter enciclopédico apenas. Representa a ênfase na divisão disciplinar do conhecimento, contrariando o princípio da interdisciplinaridade ao estabelecer uma lista fixa de tópicos disciplinares. Assim, o autor complementa sobre a mudança preterida pelo exame: "[O] Enem não alcançaria seu objetivo e contribuiria para que pouco fosse alterado nas práticas pedagógicas, uma vez que os professores diante de tal lista podem manter o ensino monodisciplinar e propedêutico". Embora Ramalho e Núñez encontrem bons resultados em sua análise da prova de 2009, que pode ter sido mais ideológica, eles defendem que o Enem não pode ser a finalidade da educação.

Sobre o antigo Enem (provas de 1998 a 2000 e sua matriz referencial), Minhoto (2003) destaca o potencial do exame para consolidar as mudanças previstas nos documentos oficiais para o ensino médio, o que na reformulação da matriz referencial no ano de 2009 passa a ser um dos objetivos do novo Enem. A autora $(2003$, p. 3) revela que a matriz de referências do exame, baseadas em habilidades e competências, parece estar pautada nas necessidades da sociedade, principalmente no que tange à esfera produtiva e tecnológica, com a finalidade de incluir o aluno de forma consciente no contexto contemporâneo. Encontra congruência entre o que está exposto na matriz de referência e a prova, contemplando situações do cotidiano e avaliação da capacidade de seleção de informações e sua utilização na resolução de problemas. Entretanto pondera que o exame pode tornar os indivíduos conformados com sua realidade, dependentes dela e não críticos sobre as mudanças que ocorrem ao seu redor (MINHOTO, 2003). Minhoto (2008) ressalta a importância do Enem enquanto meio de interferência do governo federal no ensino médio e na geração de um mercado de avaliação, no qual a União terceiriza o desenvolvimento e execução da prova, atuando de forma precária como gestora do processo.

Sousa (2003) critica a formulação da prova, que atribui a responsabilidade única e exclusivamente ao aluno sobre seu sucesso, desvinculando-o de sua realidade social e econômica. 
Os baixos resultados obtidos pelos estudantes lhes são atribuídos unicamente, como se resultassem da sua falta de esforço e empenho, sem levar em consideração a responsabilidade da escola na formação desse indivíduo e das oportunidades, ou falta delas, decorrentes do meio social. Ressalta o grande potencial do exame em condicionar os currículos escolares, uma vez que se passa a ensinar para obter méritos na prova. Essa busca, individual ou institucionalmente, gera um sentimento de individualismo e de redução do direito à educação a uma mercadoria (SOUSA, 2003). Tais fatos vão de encontro ao objetivo de democratizar a educação, como exposto na matriz de referencias de 2009.

Marcelino e Recena (2011a, 2011b) analisaram os objetivos educacionais, com base na taxonomia revisada dos objetivos educacionais, expostos pelos eixos cognitivos e por questões do novo Enem, e encontraram que o exame se baseia em eixos cognitivos que se preocupam com a aprendizagem significativa e que as questões de Química condiziam com esses pressupostos. Entretanto consideram que mais pesquisas são necessárias.

Mendonça e Silva (2010) ressaltam que as mudanças previstas nos documentos oficiais só ocorrerão com a participação ativa de professores e demais profissionais da educação, que se sentem pressionados por bons resultados apenas, gerando o marketing e competição entre escolas. Os autores (2010, p. 1) criticam a prova por seu caráter simplório e ambíguo, ao desconsiderar os diferentes contextos de um país de dimensões continentais, quando se propõe a ser contextualizada.

Explica-se a capacidade do exame de interferir na educação pela sua dimensão cultural. Como é uma prática social que pretende dar significado para a educação e requer outros agentes para funcionar, o Enem tem uma dimensão cultural, sendo constituinte de um "conjunto de sistemas ou códigos de significados que dão sentido às nossas ações” e definindo o "sistema de codificação, ordenação e regulação de modos de agir em sociedade”. Portanto, enquanto prática social importante na significação da educação, o Enem tem a capacidade de promover as mudanças nos currículos de ensino médio pela modificação dos sujeitos, uma vez que age como um sistema regulador dos modos de agir na sociedade (LOPES, LÓPEZ, 2010, p. 95). 
Uma vez que pretende a reestruturação dos currículos do ensino médio, faz-se necessário entender a concepção governamental de currículo, que está exposta na introdução aos Parâmetros Curriculares Nacionais de $5^{\mathrm{a}}$ a $8^{\mathrm{a}}$ série. Ele pode ser a listagem de matérias ou conteúdos de um curso, "Mas currículo pode significar também a expressão de princípios e metas do projeto educativo [...]. Essa foi a concepção adotada nestes Parâmetros Curriculares Nacionais" (BRASIL, 1998b, p. 49, grifo nosso).

Logo, pela mudança do currículo, o governo planeja, além da mudança dos conteúdos a serem ensinados, a redefinição dos paradigmas que justificam e norteiam a ação docente. Intendem revolucionar as práticas pedagógicas, as ferramentas de instrução e o planejamento escolar pela mudança dos objetivos e alvos do ensino. Tais mudanças não foram pensadas ao acaso, mas derivam de hibridismos e recontextualizações de discursos internacionais sobre a educação (LOPES, LÓPEZ, 2010, p. 90).

O processo de globalização trouxe mudanças para o paradigma educacional que não pararam na incorporação de novas tecnologias no âmbito de ensino e no fortalecimento de determinadas disciplinas, mas na exigência de competências e habilidades necessárias ao trabalhador para se inserir nos novos métodos de produção e trabalho capitalistas e na "valorização da sociologia como suporte para o entendimento das relações transculturais" (LOPES, LÓPEZ, 2010, p. 92).

Ao se comparar o Relatório da Comissão Internacional sobre a Educação para o Século XXI para a Unesco (DELORS et al., 1998, p. 90) com a Matriz Referencial do novo Enem, nota-se a concordância entre ambos com os paradigmas globais anteriormente expostos. $\mathrm{O}$ relatório estabelece os quatro pilares para a educação: aprender a conhecer (relacionado com a incorporação de novas tecnologias no sistema escolar e derivado da validade provisório dos conhecimentos tidos como verdade), aprender a fazer (exigências de competências e habilidades necessárias ao trabalho), aprender a conviver e aprender a ser (entendimento das relações transculturais em um mundo cada vez mais sem fronteiras), que podem ser percebidos na concepção do exame, que se baseia na avaliação da capacidade do aluno de interpretar e contextualizar os problemas do cotidiano (aprender a conhecer), do preparo para o mercado de 
trabalho (aprender a fazer) e possibilita a autoavaliação do aluno (aprender a ser, numa perspectiva de favorecimento das performances).

Como visto, o Enem se estrutura na avaliação das competências e habilidades do indivíduo, que, de acordo com seu documento básico (BRASIL, 2000a, p. 5, grifo como no original), podem assim ser definidas:

Competências são as modalidades estruturais da inteligência, ou melhor, ações e operações que utilizamos para estabelecer relações com e entre objetos, situações, fenômenos e pessoas que desejamos conhecer. As habilidades decorrem das competências adquiridas e referem-se ao plano imediato do "saber fazer". Por meio das ações e operações, as habilidades aperfeiçoam-se e articulam-se, possibilitando nova reorganização das competências.

Isso confirma a relação do Enem com os discursos globais de educação, posto que as habilidades e competências servem para a manutenção do capitalismo, uma vez que atuam como mera preparação para o mercado de trabalho, embora tragam em si características de reinterpretação e hibridismos, derivados do contexto brasileiro.

Voltando-se para os itens I e II dos objetivos do Enem, o governo revela a intenção do exame em servir como meio de autoavaliação e de seleção para o mercado de trabalho. Questiona-se aqui sua eficácia nesse sentido, uma vez que desconsidera a avaliação das habilidades técnicas e de como o aluno se relaciona em grupo, o que Bloom (1956) enquadra nos domínios afetivo e psicomotor, respectivamente, da taxonomia dos objetivos educacionais.

Em entrevista exibida no dia 10 de setembro de 2011, no Jornal Nacional da Rede Globo de televisão, o então ministro da educação Fernando Haddad, ao falar do Enem, comenta sobre o aumento da média nacional em 10 pontos de 2009 para 2010 e do aumento de participantes no exame. Sobre a comparação dos resultados do exame entre escolas, o ministro revelou a importância de não usá-los unicamente como meio de avaliação das instituições, visto que a prova deixa de lado outras dimensões da escola e não considera as diferenças entre elas, como a diferença gritante 
nos investimentos que ocorre entre as instituições públicas e particulares, que podem receber para um mês o que o governo destina para um ano todo (OLIVEIRA, 2011). Tal declaração vai de encontro ao item VI dos objetivos do exame "promover avaliação do desempenho acadêmico das escolas de ensino médio", como expresso na própria documentação do exame, e gera dúvidas quanto à coerência da prova ou de sua base legal.

Devido à grande influência do exame na prática docente, ao mesmo tempo em que possui incoerências em sua matriz referencial, como demonstram as pesquisas, este trabalho pretende analisar possíveis mudanças nos currículos educacionais, no que tange aos conteúdos, práticas pedagógicas e ideologias causadas pelo novo Enem. Para isso, foi utilizada como referencial de análise da Matriz de Referência de 2009 a Taxonomia Revisada dos Objetivos Educacionais, a fim de contribuir para o planejamento das escolas da rede pública de ensino, identificando norteadores para a prática pedagógica influenciados pelo novo Enem e refletindo sobre possíveis mudanças nos currículos escolares de Química.

\section{CURRÍCULO NA EDUCAÇÃO}

As teorias sobre currículos surgiram primeiramente nos Estados Unidos da América por volta de 1920, devido à rápida expansão da escolarização gerada pela industrialização acelerada. Os primeiros currículos se pautavam em objetos e procedimentos para alcançar determinados resultados e sua avaliação, além de ter a preocupação com uma formação especializada para o trabalho, para a vida acadêmica em geral e a estipulação de objetivos educacionais (baseados em necessidades dos alunos e sociais). Esse modelo foi chamado de tradicional, e pode, então, ser resumido em: "conteúdos, objetivos e ensino destes conteúdos de forma eficaz para ter a eficiência nos resultados" de forma neutra (HORNBURG, SILVA, 2007, p. 62).

Outras teorias curriculares que sucederam à tradicional, como as críticas e pós-críticas, discorreram sobre a falsa neutralidade dos currículos tradicionais. Os currículos passaram a ser analisados não como simples transmissão de fatos, mas de significados sociais, em uma análise marxista. O currículo 
passou a ser visto como um meio de manter a cultura dominante, suas relações de poder e demais princípios (HORNBURG, SILVA, 2007). Lopes (2004, p. 111) se cita (1999) ao falar do currículo:

Trata-se de um processo de seleção e de produção de saberes, de visões de mundo, de habilidades, de valores, de símbolos e significados, portanto, de culturas, capaz de instituir formas de organizar o que é selecionado, tornando-o apto a ser ensinado.

Após a revolução industrial, com o surgimento da globalização, disseminou-se pelo mundo, especialmente nos países ocidentais, uma política global para a educação. Ball (apud LOPES, LÓPEZ, 2010), citando Carter e O'Neil, indica os cinco elementos circulantes com essa política:

a. escola vista como empresa,

b. formação eficaz de mão de obra por meio de desenvolvimento de competências e habilidades,

c. controle do conteúdo e sua avaliação como foco nos desempenhos de discentes e docentes,

d. redução de custos,

e. participação da comunidade e das exigências do mercado nas decisões da escola.

Ao se focar no saber-fazer (inspirado pelas habilidades e competências) e na competividade (pelo estabelecimento de rankings), o exame converge economia e educação para o mesmo ponto. Assim, o conhecimento é legitimado não por sua veracidade, mas pela sua eficácia (LOPES, LÓPEZ, 2010). O estabelecimento de comparação entre escolas e professores e a abrangência de finalidades atribuídas ao Enem permitem ao governo o controle sobre os currículos escolares, ao mesmo tempo em que age como avaliação da eficácia dos agentes da educação.

Competência é a capacidade de "mobilizar conhecimentos, valores e decisões para agir de modo pertinente numa determinada situação" (MELLO apud DORNELES, ALVES, 2010, p. 134). Mas, na visão de Lopes e López (2010), acaba por se limitar apenas ao "saber-fazer", inserindo-se em uma perspectiva curricular de valorização do desempenho e eficácia, contribuindo para o que a autora chama de política de performatividade que, de acordo com Ball (apud LOPES, LÓPEZ, 2010, p. 97), trata 
de "uma tecnologia, uma cultura e um modo de regulação que emprega julgamentos, comparações e termina se revelando como meio de controle, de desgaste e de mudança". Evidencia-se a visão de currículo como sequência de conteúdos a serem ministrados e a formação de rankings como características da cultura de performatividade, cujas consequências são a manutenção dos valores capitalistas, como o individualismo, a mercantilização da educação e a legitimação do conhecimento pela sua eficácia e não pelo seu caráter de verdade (LOPES, LÓPEZ, 2010, p. 90). Nota-se pelos itens VI e VII (BRASIL, 2009a) que o governo federal cobra a eficiência e maximização ao estabelecer comparação entre as instituições de ensino médio e entre os alunos: mais um traço da politica de performatividade.

O intuito de servir como base para autoavaliação, presente desde o início da prova em 1998, mostra uma tendência do Enem de instaurar a autorregulação, da maneira que os indivíduos se tornam responsáveis pela maximização de seus resultados sem, supostamente, usar métodos de repressão (LOPES, LÓPEZ, 2010). Impõem-se ao indivíduo os valores capitalistas, corroborando para a individualidade e a busca por eficácia, independentemente dos resultados colaterais, ou seja, desconsiderando os efeitos sociais e ambientais dos atos.

Percebe-se a relação entre o exame e a teoria tradicional de currículo, no que tange à valorização da eficácia. Entretanto, é indiscutível a influência da política global no desenvolvimento do currículo e na sociedade. Logo, quando o Enem tenta induzir a reestruturação nos currículos do ensino médio, produz também mudanças nos modos de agir em sociedade, interferindo nas relações entre dominante e dominado, ou seja, nas relações de poder.

\section{TAXONOMIA (REVISADA) DE BLOOM}

A taxonomia de Bloom, criada na década de 1950, num período de preocupação com a formação de mão de obra qualificada para o trabalho e em meio à expansão do sistema escolar, decorreu da necessidade de especificar quais os objetivos educacionais almejados e como avaliar a sua eficiência, enquanto o currículo era visto como conteúdo, metodologia e avaliação 
da prática pedagógica. Nesse sentido, a taxonomia tinha a pretensão de ser neutra (BLOOM, 1956, p. 6) em relação a concepções de ensino, aprendizagens e políticas, embora note-se em sua concepção traços do comportamentalismo e de resposta às demandas sociais da época. Observa-se também a sua relação com a teoria tradicional de currículo.

A taxonomia dos objetivos educacionais, ou taxonomia de Bloom, como também é conhecida, foi criada para facilitar a troca de ideias e material entre avaliadores e outras pessoas encarregadas de pesquisas educacionais e desenvolvimento de currículos, uma vez que alguns objetivos da área podem ter significados abrangentes, como "pensar" e "resolver problemas". A taxonomia também poderia apontar inúmeros erros nos campos da educação e avaliação (BLOOM, 1956).

Bloom acreditava que a taxonomia poderia servir como:

a. linguagem comum para facilitar a comunicação;

b. base para determinar o significado de objetivos educacionais abrangentes;

c. meio de determinar congruência entre objetivos, atividades e avaliação;

d. panorama dos objetivos em extensão e profundidade em um curso ou currículo (KRATHWOHL, 2002, p. 212).

Assim, a taxonomia foi usada para verificar a extensão dos objetivos educacionais de currículos de ensino, como exemplo de níveis maiores a serem explorados e de "valia na classificação de material de teste" (MORRIS, 1961 apud BLOOM, KRATHWOHL, MASIA, 1974, p. 10).

Na avaliação de currículos de ensino e documentos oficiais, um dos problemas encontrados foi a extensão de significados inerentes a certos objetivos. Entretanto, pôde-se fazer uma aproximação com base no sentido geral do texto (BLOOM, 1956). A classificação de objetivos de exercícios de avaliações mostrou-se mais complicada, uma vez que os conhecimentos anteriores do aluno interferiam na resolução do exercício, podendo ocorrer uma gama de processos cognitivos diferentes. Assim, poder-se-ia esperar que o aluno aplicasse um procedimento, mas ele já poderia ter memorizado a resolução e apenas a transcreveria. Torna-se necessário saber quais situações de aprendizagem precederam o teste, ou mesmo pressupô-las (BLOOM, 1956, p. 51). 
A taxonomia não tenta classificar os métodos de instrução usados pelos educadores, os materiais que usam ou a forma como se relacionam com os alunos, mas classificar as maneiras como se espera que os alunos ajam, pensem ou sintam como resultado do processo de ensino (BLOOM, 1956, p. 12). Com base no que se espera dos alunos, pode-se inferir quais os métodos didáticos mais adequados.

Os objetivos educacionais são definidos como a descrição das maneiras pelas quais os alunos serão modificados por meio do processo educativo (BLOOM, 1956, p. 26), ou seja, como eles serão mudados em seu pensar, agir e sentir. Dentre as muitas formas de se escolher os objetivos aplicados aos alunos, destaca-se um: aquele que decorre de investigações da vida contemporânea, seus problemas e condições e as oportunidades geradas por ela (BLOOM, 1956). Essa ideia aproxima-se muito da teoria tradicional de currículo (HORNBURG, SILVA, 2007, p. 62).

A taxonomia original foi planejada sobre três domínios: cognitivo, afetivo e psicomotor. O domínio afetivo está relacionado "a sentimentos e posturas. Envolve categorias ligadas ao desenvolvimento da área emocional e afetiva, que incluem comportamento, atitude, responsabilidade, respeito, emoção e valores", e suas categorias hierárquicas são "receptividade, resposta, valorização, organização e caracterização", sendo necessário desempenho adequado na anterior para avançar para outra de maior complexidade (FERRAZ, BELHOT, 2010, p. 423). Essas categorias seguem um contínuo de internalização do objeto e de valores sociais, portanto seu papel é crítico na criação da consciência (BLOOM, KRATHWOHL, MASIA, 1974, p. 38) e indispensável seu desenvolvimento em atividades educacionais, neste momento em que a formação do pensamento crítico e da cidadania são tão valorizadas. Foi o domínio de maior dificuldade em se fazer uma taxonomia, uma vez que os objetivos eram vagos e sentimentos internos eram tão importantes quanto as suas manifestações: os comportamentos (BLOOM, 1956, p. 7). Embora tenha sua importância, principalmente no que tange às relações sociais e posturas frente a problemas, era pouco valorizado e continua sendo.

O domínio psicomotor não foi criado por Bloom, que, embora admitisse sua existência, não considerava útil a criação de 
uma taxonomia para ele, uma vez que objetivos nesse domínio eram pouco vistos em escolas (BLOOM, 1956, p. 7). Outros pesquisadores, entretanto, viram a importância desse domínio no desenvolvimento de habilidades físicas e criaram uma taxonomia específica baseada nas categorias hierárquicas "imitação, manipulação, articulação e naturalização", sendo que o cumprimento de uma é necessário para o avanço para outra mais complexa (FERRAZ, BELHOT, 2010, p. 423). Assim, esse domínio se pauta no desenvolvimento de reflexos, percepção, habilidades físicas e comunicação não verbal.

De acordo com os Parâmetros Curriculares Nacionais $\mathrm{PCN}$ - para o ensino médio, "este documento $[\mathrm{PCN}]$ procura apresentar, [...] uma proposta para o Ensino Médio que, sem ser profissionalizante, efetivamente propicie um aprendizado útil à vida e ao trabalho" (BRASIL, 2000a, p. 4). O domínio afetivo (BLOOM, 1956, p. 7) está relacionado a sentimentos e posturas ligadas a mudanças no "comportamento, atitude, responsabilidade, respeito, emoção e valores” (FERRAZ, BELHOT, 2010, p. 423). O desenvolvimento desse nível e seu conhecimento são cruciais para o mercado de trabalho, que envolve relações sociais complexas e diversificadas, com necessidade de atitudes e posturas adequadas para as mais diferenciadas situações. Não se alcança esse objetivo com provas objetivas e individuais, desconsiderando-se a afetividade e o trabalho em grupo. Já o domínio psicomotor está ligado a habilidades físicas, como reflexo, percepção, movimentos aperfeiçoados e comunicação não verbal (FERRAZ, BELHOT, 2010, p. 423). A avaliação desse domínio é de extrema importância para o aluno e para o potencial empregador, que pode buscar habilidades físicas específicas (associadas às afetivas e cognitivas) necessárias para determinada função. Para que o objetivo de servir como meio de entrada no mercado de trabalho seja realmente alcançado de forma adequada, é necessário que se vá além da avaliação do domínio cognitivo, por meio de atividades diferenciadas de prova objetiva, que prezem pelo trabalho em grupo e outras formas de comunicação, além da escrita.

O terceiro domínio, o cognitivo, está relacionado a aprender, tanto ao ato de adquirir conhecimentos, como o desenvolvimento intelectual e de habilidades e competências (FERRAZ, BELHOT, 2010, p. 422). Originalmente, eram seis categorias em 
uma dimensão, mas na revisão houve separação em duas dimensões: a do Conhecimento e a do Processo cognitivo.

Um esquema resumido da taxonomia original é descrito no quadro 1.

QUADRO 1 - Estrutura da taxonomia original dos objetivos Educacionais, proposta por Bloom

\begin{tabular}{|c|c|}
\hline CATEGORIA & SUBCATEGORIA \\
\hline \multirow{3}{*}{ 1. Conhecimento } & $\begin{array}{l}\text { 1.1 Conhecimento de detalhes } \\
\text { 1.1.1 Conhecimento de terminologia } \\
\text { 1.1.2 Conhecimento de fatos específicos }\end{array}$ \\
\hline & $\begin{array}{l}\text { 1.2 Conhecimento de jeitos e caminhos de ligar com detalhes } \\
\text { 1.2.1 Conhecimento de convenções } \\
\text { 1.2.2 Conhecimento de tendências e sequências } \\
\text { 1.2.3 Conhecimento de classificações e categorias } \\
\text { 1.2.4 Conhecimento de critérios } \\
\text { 1.2.5 Conhecimento de metodologia }\end{array}$ \\
\hline & $\begin{array}{l}\text { 1.3 Conhecimento de generalizações e abstrações em um campo } \\
\text { 1.3.1 Conhecimento dos princípios e generalizações } \\
\text { 1.3.2 Conhecimento de teorias e estruturas }\end{array}$ \\
\hline \multirow{3}{*}{ 2. Compreensão } & 2.1 Tradução \\
\hline & 2.2 Interpretação \\
\hline & 2.3 Extrapolação \\
\hline \multicolumn{2}{|l|}{ 3. Aplicação } \\
\hline \multirow{3}{*}{ 4. Análise } & 4.1 Análise de elementos \\
\hline & 4.2 Análise de relações \\
\hline & 4.3 Análise de princípios organizacionais \\
\hline \multirow{3}{*}{ 5. Síntese } & 5.1 Produção de uma comunicação única \\
\hline & 5.2 Produção de um plano, ou conjunto proposto de operações \\
\hline & 5.3 Derivação de um conjunto de relações abstratas \\
\hline \multirow{2}{*}{ 6. Avaliação } & 6.1 Avaliação em termos de evidências internas \\
\hline & 6.2 Avaliação em termos de critérios externos \\
\hline
\end{tabular}

Fonte: Krathwohl (2002, p. 213).

Definiu-se conhecimento como a capacidade de lembrar ou reconhecer uma ideia ou fenômeno que o aluno tenha experienciado nos processos escolares (BLOOM, 1956). Entretanto, Krathwohl modifica essa definição na revisão da taxonomia e o conhecimento passa a ser o assunto, o conteúdo, do qual o objetivo educacional trata tão somente, sem envolver estritamente processos como lembrar ou reconhecer (2002, p. 214).

$\mathrm{Na}$ taxonomia original, há a diferenciação dos termos arts e skills (artes e competências) de ability (habilidade). O primeiro se refere a modos de operação e de técnicas gerais para lidar com problemas, enquanto o segundo se refere a técnicas 
específicas para solucionar um problema novo, sendo consideradas a soma de "conhecimento", como concebido na taxonomia original, e arts ou skills (BLOOM, 1956, p. 38-39).

Tais conceitos se assemelham muito com os de habilidades e competências do documento básico do Enem (BRASIL, 2000a). Arts e skills podem ser comparados com as competências, no que tange ao caráter geral das técnicas e aplicabilidade, enquanto ability pode ser entendida como habilidade, no que se refere à especificidade dos processos. Nota-se que Bloom englobou as competências dentro de habilidades, valorizando a especificidade do conhecimento. No documento supracitado, valoriza-se a generalidade das competências, colocando-se as habilidades como suas partes constituintes.

Bloom (1956, p. 39-40) defende o ensino das habilidades e competências, uma vez que a ciência está progredindo cada vez mais rápido, tornando conhecimentos hoje aceitos em mitos amanhã, isso já em 1956. Ele ressalta o caráter parcial dos conhecimentos, que não são aplicados a todas as situações, visto que cada qual possui suas peculiaridades, valorizando assim as "habilidades", que são mais específicas, do que as "competências". Defende o bem causado à sociedade, pois seus indivíduos estarão mais capacitados para as futuras escolhas, como, por exemplo, o voto, desenvolvendo o que pode ser chamado de pensamento "crítico" ou "reflexivo". Entretanto, o ensino de habilidades e competências tem se limitado ao saber-fazer. Nessa perspectiva, valoriza-se a busca pelo desempenho individual e estimula-se a competição, contribuindo não para o saber conviver, mas para a valorização da individualidade (LOPES, LÓPEZ, 2010).

\section{A REVISÃo}

A taxonomia foi revisada em 2001 para atender às descobertas na área de ensino-aprendizagem, como o conceito de aprendizagem significativa, embora mantenha o continuum de complexidade e abstração da taxonomia original. Uma das maiores diferenças da revisão para a taxonomia original é a separação da dimensão do conhecimento e da dimensão dos processos cognitivos. O primeiro diz respeito ao assunto ou conteúdo que deve ser aprendido - o conhecimento -, enquanto 
o segundo refere-se ao que deve ser feito com o conteúdo. A categoria Conhecimento da taxonomia original deu origem ao domínio do conhecimento e ao processo cognitivo Lembrar, enquanto o restante designou outros processos.

Os dois domínios são apresentados nos quadros 2 e 3.

QUADRO 2 - Estrutura da dimensão do conhecimento na taxonomia revisada dos objetivos educacionais

\begin{tabular}{|c|c|}
\hline CATEGORIAS & SUBCATEGORIAS \\
\hline $\begin{array}{l}\text { A. Conhecimento factual - } \\
\text { os conhecimentos básicos que os } \\
\text { estudantes devem saber para estarem } \\
\text { familiarizados com a disciplina e } \\
\text { resolver problemas nela }\end{array}$ & $\begin{array}{l}\text { A.a Conhecimento de terminologia } \\
\text { A.b Conhecimento de detalhes } \\
\text { específicos e elementos }\end{array}$ \\
\hline \multirow{3}{*}{$\begin{array}{l}\text { B. Conhecimento conceitual - as } \\
\text { interrelações entre elementos básicos } \\
\text { dentros de uma estrutura maior que as } \\
\text { permite funcionar juntas }\end{array}$} & $\begin{array}{l}\text { B.a Conhecimento de classificações } \\
\text { e categorias }\end{array}$ \\
\hline & $\begin{array}{l}\text { B.b Conhecimento de princípios } \\
\text { e generalizações }\end{array}$ \\
\hline & $\begin{array}{l}\text { B.c Conhecimento de teorias, modelos } \\
\text { e estruturas }\end{array}$ \\
\hline \multirow{3}{*}{$\begin{array}{l}\text { C. Conhecimento procedimental - } \\
\text { como fazer algo; métodos de pesquisa, } \\
\text { critérios para usar habilidades, } \\
\text { algorítimos, técnicas e métodos }\end{array}$} & $\begin{array}{l}\text { C.a Conhecimento de habilidades de } \\
\text { assuntos específicos e algorítmos }\end{array}$ \\
\hline & $\begin{array}{l}\text { C.b Conhecimento de técnicas de } \\
\text { assuntos específicos e métodos }\end{array}$ \\
\hline & $\begin{array}{l}\text { C.c Conhecimento de critérios } \\
\text { para determinar quando usar um } \\
\text { procedimento apropriado }\end{array}$ \\
\hline \multirow{3}{*}{$\begin{array}{l}\text { D. Conhecimento metacognitivo - } \\
\text { conhecimento de cognição em geral, } \\
\text { bem como de conscientização e } \\
\text { conhecimento de sua própria cognição }\end{array}$} & D.a Conhecimento estratégico \\
\hline & $\begin{array}{l}\text { D.b Conhecimento de tarefas } \\
\text { cognitivas, incluindo conhecimento } \\
\text { contextual e condicional apropriado }\end{array}$ \\
\hline & D.c Autoconhecimento \\
\hline
\end{tabular}

Fonte: Krathwohl (2002, p. 214).

Na dimensão do conhecimento surge uma nova categoria, a do Conhecimento metacognitivo, já que as outras estavam inseridas em 1. Conhecimento. Essa nova categoria tem se tornado muito importante na área de ensino (FERRAZ, BELHOT, 2010, p. 425). Desde a criação da taxonomia original, uma tendência se instaurou na psicologia e educação: a metacognição, que está presente em várias teorias de ensino (das neo-Piagetianas às Vygotskianas), sendo consenso que o aumento da metacognição corrobora para uma melhor aprendizagem (PINTRICH, 2002, p. 219). A importância desse conhecimento é decorrente do aumento da possibilidade de autoaprendizagem e seu controle, possibilitada 
pela "utilização da tecnologia da comunicação na educação, a criação de novas oportunidades educacionais e a popularização da modalidade a distância” (FERRAZ, BELHOT, 2010, p. 425). Para essa avaliação, seria necessário investigar o comportamento do aluno durante a realização de tarefas, para que se pudesse notar o uso de estratégias e conhecimentos sobre o aprendizado, como o "pensar alto", fazer anotações, etc. (MAYER, ALEXANDER, 2011, p. 206). Ainda que sob o objetivo de autoavaliação, o Enem não possibilita ao aluno aprender sobre autoconhecimento, considerar o uso de estratégias para melhorar a aprendizagem e muito menos avaliar esse tipo de conhecimento, pois não oferece meios de analisar o processo que o aluno usou para resolver a avaliação.

QUADRO 3 - Estrutura da dimensão do processo cognitivo na taxonomia revisada dos objetivos educacionais

\begin{tabular}{|c|c|}
\hline CATEGORIAS & SUBCATEGORIAS \\
\hline $\begin{array}{l}\text { 1. Lembrar - Buscar conhecimento relevante } \\
\text { na memória de longo termo }\end{array}$ & $\begin{array}{l}\text { 1.1 Reconhecendo } \\
\text { 1.2 Lembrando }\end{array}$ \\
\hline $\begin{array}{l}\text { 2. Entender - Determinar o significado de } \\
\text { mensagens instrucionais, incluindo comunicação } \\
\text { oral, escrita e gráfica }\end{array}$ & $\begin{array}{l}2.1 \text { Interpretando } \\
\text { 2.2 Exemplificando } \\
\text { 2.3Classificando } \\
2.4 \text { Resumindo } \\
2.5 \text { Inferindo } \\
\text { 2.6 Comparando } \\
\text { 2.7Explicando }\end{array}$ \\
\hline $\begin{array}{l}\text { 3. Aplicar - Executar ou usar um procedimento } \\
\text { em uma dada situação }\end{array}$ & $\begin{array}{l}\text { 3.1 Executando } \\
\text { 3.21mplementando }\end{array}$ \\
\hline $\begin{array}{l}\text { 4. Analisar - Quebrar o material em suas } \\
\text { partes constituintes e detectar como } \\
\text { as partes se relacionam entre si e com } \\
\text { o a estrutura ou propósito no todo }\end{array}$ & $\begin{array}{l}\text { 4.1 Diferenciando } \\
4.2 \text { Organizando } \\
4.3 \text { Atribuindo }\end{array}$ \\
\hline $\begin{array}{l}\text { 5. Avaliar - Fazer julgamentos baseado em } \\
\text { critérios e padrões }\end{array}$ & $\begin{array}{l}5.1 \text { Checando } \\
5.2 \text { Criticando }\end{array}$ \\
\hline $\begin{array}{l}\text { 6. Criar - Unir elementos para formal um tudo } \\
\text { coerente e novo ou fazer um produto original }\end{array}$ & $\begin{array}{l}6.1 \text { Gerando } \\
6.2 \text { Planejando } \\
6.3 \text { Produzindo }\end{array}$ \\
\hline
\end{tabular}

Fonte: Elaboração dos autores.

Com a divisão em dois domínios, é possível criar a Tabela dos objetivos educacionais (Tabela 1) e avaliar objetivos de 
um curso, currículo ou avaliação em extensão e profundidade. A distribuição dos objetivos na tabela mostra a ênfase ou o descuido em relação a certos objetivos educacionais, possibilitando uma melhor avaliação da prática pedagógica (KRATHWOHL, 2002). A tabela pode ser consultada a seguir.

TABELA 1 - Tabela dos objetivos educacionais da taxonomia revisada de Bloom

\begin{tabular}{|c|c|c|c|c|c|c|}
\hline \multicolumn{7}{|c|}{ DIMENSÃO DO PROCESSO COGNITIVO } \\
\hline $\begin{array}{l}\text { Dimensão do } \\
\text { conhecimento }\end{array}$ & 1. Lembrar & 2. Entender & 3. Aplicar & 4. Analisar & 5. Avaliar & 6. Criar \\
\hline $\begin{array}{l}\text { A. Conhecimento } \\
\text { factual }\end{array}$ & & & & & & \\
\hline $\begin{array}{l}\text { B. Conhecimento } \\
\text { conceitual }\end{array}$ & & & & & & \\
\hline $\begin{array}{l}\text { C. Conhecimento } \\
\text { procedimental }\end{array}$ & & & & & & \\
\hline $\begin{array}{l}\text { D. Conhecimento } \\
\text { metacognitivo }\end{array}$ & & & & & & \\
\hline
\end{tabular}

Fonte: Krathwohl (2002, p. 216).

Embora criada originalmente há muito tempo sob paradigmas educacionais diferentes dos atuais, a taxonomia é uma ferramenta eficaz para o esclarecimento dos objetivos educacionais. A sua revisão recente incorporou as descobertas recentes na área de ensino-aprendizagem e os princípios norteadores da educação sem perder a eficiência, mas, ao contrário, facilitando a análise.

Em comparação com a aprendizagem significativa de D. Ausubel, Mayer (2002, p. 227) diz que a aprendizagem significativa ocorre quando o aluno constrói não só o conhecimento, mas os processos cognitivos necessários para a resolução de um problema que seja desconhecido. Para tanto, é necessário que a instrução vá além do conhecimento factual e de processos cognitivos superiores a lembrar (MAYER, 2002, p. 227).

O Enem foi estruturado para estar de acordo com os paradigmas educacionais globais. Diversas pesquisas demonstram suas influências para a constituição dos sujeitos e definição da identidade social, revelando tendência para a manutenção dos princípios capitalistas, por meio da cultura da performatividade. Uma análise dos objetivos educacionais subjacentes na matriz de referência do Enem pode indicar o que se espera 
do aluno, identificando os conteúdos, práticas pedagógicas e ideologias norteadoras da prova.

\section{METODOLOGIA}

A pesquisa foi de cunho qualitativo e exploratório, e seus dados foram coletados na Matriz de Referência do Exame Nacional do Ensino Médio de 2009. O documento oficial foi analisado de acordo com a taxonomia revisada dos objetivos educacionais.

Fez-se a análise das Habilidades e Competências da área de Ciências da Natureza e suas Tecnologias, expostas na Matriz de Referência do novo Enem (BRASIL, 2009a), disponível nos sites governamentais. Como ferramenta de análise, usou-se a taxonomia revisada de Bloom (KRATHWOHL, 2002; MAYER, 2002) para identificar que tipo de conhecimento o Enem valoriza e pretende que o aluno adquira, e como deve ser esse processo. Logo, separaram-se no texto da matriz as habilidades e competências que se relacionam com o conhecimento de Química e/ou de Ciências, excluindo aqueles que se relacionavam mais às disciplinas de Física e Biologia. Não se trata de renegar a dimensão química inerente a esses processos, mas de uma restrição meramente analítica àqueles processos tão gerais que englobem a química, ou seja, que tratem de ciências, ou que se direcionem especificamente à Química.

Depois da seleção, analisou-se separadamente cada texto. Como são descrições das mudanças esperadas que os alunos tenham sofrido nos anos de educação, caracterizam-se como objetivos educacionais e, portanto, possuem um verbo central, determinando o que se espera que o aluno faça com o conhecimento - dimensão do processo cognitivo -, e um ou mais substantivos que descrevem o tipo de conhecimento - dimensão do conhecimento (KRATHWOHL, 2002). Os dados foram agrupados em quadros e comparados entre si e com demais dados da literatura.

Como afirmam diversos autores, a prova possui grande possibilidade de induzir mudanças nos currículos de ensino. Propõe-se uma reflexão, com base nas análises citadas acima e nos dados seguintes, sobre quais mudanças serão essas e sua influência no sistema escolar. 


\section{RESULTADOS E DISCUSSÃO}

A análise das competências e habilidades é apresentada no quadro 4, conforme nossa interpretação por meio da comparação entre as habilidades e competências expostas na matriz com as categorias e subcategorias da taxonomia revisada dos objetivos educacionais. Os processos cognitivos estão destacados nos textos em negrito e os tipos de conhecimento, em itálico.

\section{QUADRO 4 - Competências de Química e Ciências da matriz de referência do Enem 2009 e seus objetivos educacionais}

\begin{tabular}{|c|c|c|}
\hline \multirow{2}{*}{ COMPETÊNCIAS } & \multicolumn{2}{|c|}{ DIMENSÃO } \\
\hline & PROCESSO COGNITIVO & CONHECIMENTO \\
\hline $\begin{array}{l}\text { Competência de área } 1 \text { - Compreender } \\
\text { as ciências naturais e as tecnologias } \\
\text { a elas associadas como construções } \\
\text { humanas, percebendo seus papéis } \\
\text { nos processos de produção e no } \\
\text { desenvolvimento econômico e social } \\
\text { da humanidade }\end{array}$ & $\begin{array}{l}\text { 2. Entender } \\
2.5 \text { Entender } \\
\text { inferindo }\end{array}$ & $\begin{array}{l}\text { B. Conceitual } \\
\text { B.c Conceitual } \\
\text { de estruturas }\end{array}$ \\
\hline $\begin{array}{l}\text { Competência de área } 2 \text { - Identificar } \\
\text { a presença e aplicar as tecnologias } \\
\text { associadas às ciências naturais em } \\
\text { diferentes contextos }\end{array}$ & $\begin{array}{l}\text { 1.1 Lembrar } \\
\text { reconhecendo } \\
\text { 3.1 Aplicar executando }\end{array}$ & $\begin{array}{l}\text { C.b } \\
\text { Procedimental } \\
\text { de técnicas }\end{array}$ \\
\hline $\begin{array}{l}\text { Competência de área } 3 \text { - Associar } \\
\text { intervencões que resultam em } \\
\text { degradação ou conservação ambiental } \\
\text { a processos produtivos e sociais } \\
\text { e a instrumentos ou ações científico- } \\
\text {-tecnológicos }\end{array}$ & $\begin{array}{l}\text { 2. Entender } \\
2.5 \text { Entender } \\
\text { inferindo }\end{array}$ & $\begin{array}{l}\text { C.b } \\
\text { Procedimental } \\
\text { de métodos }\end{array}$ \\
\hline $\begin{array}{l}\text { Competência de área } 4 \text { - Relacionada } \\
\text { à biologia }\end{array}$ & & \\
\hline $\begin{array}{l}\text { Competência de área } 5 \text { - Entender } \\
\text { métodos e procedimentos próprios } \\
\text { das ciências naturais e aplicá-los em } \\
\text { diferentes contextos }\end{array}$ & $\begin{array}{l}\text { 2. Entender } \\
\text { 3.1 Aplicar } \\
\text { executando }\end{array}$ & $\begin{array}{l}\text { C.c } \\
\text { Procedimental } \\
\text { de critérios }\end{array}$ \\
\hline $\begin{array}{l}\text { Competência de área } 7 \text { - Apropriar-se } \\
\text { de conhecimentos da química para, } \\
\text { em situações problema, interpretar, } \\
\text { avaliar ou planejar intervenções } \\
\text { científico-tecnológicas }\end{array}$ & 3. Aplicar & $\begin{array}{l}\text { B.c Conceitual } \\
\text { de estruturas }\end{array}$ \\
\hline $\begin{array}{l}\text { Competência de área } 8 \text { - Relacionada } \\
\text { à biologia }\end{array}$ & $\begin{array}{l}2.1 \text { Entender } \\
\text { interpretando } \\
\text { 5.0 Avaliar } \\
\text { 6.0 Criar }\end{array}$ & $\begin{array}{l}\text { C.c } \\
\text { Procedimental } \\
\text { de critérios }\end{array}$ \\
\hline
\end{tabular}

Fonte: Elaboração dos autores. 
As informações acima foram colocadas na Tabela taxonômica (Tabela 2), onde é possível perceber a ênfase dada pelas competências. Percebe-se que a maioria das competências está associada à categoria $\mathrm{C}$. Conhecimento procedimental, apenas três objetivos vinculam-se a B. Conhecimento conceitual e nenhuma ao nível A. Conhecimento factual. Como as competências são capacidades de reunir conhecimentos para agir em situações diversas, já era de se esperar que se voltassem ao conhecimento do tipo procedimental, pois, como defende Mello (apud DORNELES, ALVES, 2010, p. 134), “a competência só pode ser construída na prática”. Entretanto, podem acabar pautando-se apenas no "saber-fazer", valorizando o relembrar de procedimentos, fórmulas e algoritmos para a resolução de problemas, sem, no entanto, avaliar se o aluno tem o entendimento de conceitos relativos a esses processos. Nesse caso, contrariam a si mesmas, deixando de exigir a criatividade e inovação e tornando-se mais uma técnica a ser lembrada.

TABELA 2 - Tabela taxonômica dos objetivos educacionais subjacentes às competências da matriz de referência das ciências da natureza e suas tecnologias do Enem 2009

\begin{tabular}{|c|c|c|c|c|c|c|}
\hline \multicolumn{7}{|c|}{ DIMENSÃO DO PROCESSO COGNITIVO } \\
\hline $\begin{array}{l}\text { Dimensão do } \\
\text { conhecimento }\end{array}$ & 1. Lembrar & 2. Entender & 3. Aplicar & 4. Analisar & 5. Avaliar & 6. Criar \\
\hline $\begin{array}{l}\text { A. Conhecimento } \\
\text { factual }\end{array}$ & - & - & - & - & - & - \\
\hline $\begin{array}{l}\text { B. Conhecimento } \\
\text { conceitual }\end{array}$ & - & 2 & 1 & - & - & - \\
\hline $\begin{array}{l}\text { C. Conhecimento } \\
\text { procedimental }\end{array}$ & 1 & 3 & 2 & - & 1 & 1 \\
\hline $\begin{array}{l}\text { D. Conhecimento } \\
\text { metacognitivo }\end{array}$ & - & - & - & - & - & - \\
\hline
\end{tabular}

Fonte: Krathwohl (2002, p. 216).

Quanto aos processos cognitivos, quase todos estão envolvidos, exceto 4. Analisar. Entretanto, como seguem um continuum de complexidade e abstração, incorporam categorias inferiores ao tratarem de outras em níveis superiores. A ênfase fica nos processos 2. Entender e 3. Aplicar, sendo este último o esperado para as competências, devido ao seu caráter procedimental. Entretanto, questiona-se se esses processos são efetivos, uma vez que o aluno pode utilizar processos cognitivos de menor complexidade, como 1. Lembrar, para recuperar da memória os procedimentos e 
aplicá-los. Por isso, Bloom ressalta a necessidade de conhecer o que o aluno já sabe antes de se propor ou analisar uma avaliação, para que se saiba com maior exatidão os processos cognitivos usados pelos alunos (BLOOM, 1956, p. 51).

\section{QUADRO 5 - Habilidades de Química e Ciências da matriz de referência do Enem 2009 e seus objetivos educacionais}

\begin{tabular}{|c|c|c|}
\hline \multirow[b]{2}{*}{ HABILIDADES } & \multicolumn{2}{|c|}{ DIMENSÃO } \\
\hline & $\begin{array}{l}\text { Processo } \\
\text { cognitivo }\end{array}$ & Conhecimento \\
\hline \multicolumn{3}{|l|}{ H1 - Relacionada à física } \\
\hline $\begin{array}{l}\text { H2 - Associar a solução de problemas de } \\
\text { comunicação, transporte, saúde ou outro, } \\
\text { com o correspondente desenvolvimento científico } \\
\text { e tecnológico }\end{array}$ & $\begin{array}{l}2.5 \text { Entender } \\
\text { inferindo }\end{array}$ & $\begin{array}{l}\text { C.b Procedimental } \\
\text { de métodos }\end{array}$ \\
\hline $\begin{array}{l}\text { H3 - Confrontar interpretações científicas com } \\
\text { interpretações baseadas no senso comum, } \\
\text { ao longo do tempo ou em diferentes culturas }\end{array}$ & & $\begin{array}{l}\text { B.c Conceitual } \\
\text { de estruturas }\end{array}$ \\
\hline $\begin{array}{l}\text { H4 - Avaliar propostas de intervenção no ambiente, } \\
\text { considerando a qualidade da vida humana ou } \\
\text { medidas de conservação, recuperação ou utilização } \\
\text { sustentável da biodiversidade }\end{array}$ & $\begin{array}{l}\text { 5.1 Avaliar } \\
\text { checando }\end{array}$ & $\begin{array}{l}\text { C.c } \\
\text { Procedimental } \\
\text { de critérios }\end{array}$ \\
\hline \multicolumn{3}{|l|}{ H5 - Relacionada à física } \\
\hline \multirow{2}{*}{$\begin{array}{l}\text { H6 - Relacionar informações para compreender } \\
\text { manuais de instalação ou utilização de aparelhos, } \\
\text { ou sistemas tecnológicos de uso comum }\end{array}$} & $\begin{array}{l}\text { 4.1 Analisar } \\
\text { diferenciando }\end{array}$ & \multirow{2}{*}{$\begin{array}{l}\text { A.b Factual } \\
\text { de detalhes } \\
\text { e elementos } \\
\text { específicos }\end{array}$} \\
\hline & $\begin{array}{l}2.1 \text { Entender } \\
\text { interpretando }\end{array}$ & \\
\hline $\begin{array}{l}\text { H7 - Selecionar testes de controle, parâmetros ou } \\
\text { critérios para a comparação de materiais e produtos, } \\
\text { tendo em vista a defesa do consumidor, a saúde do } \\
\text { trabalhador ou a qualidade de vida }\end{array}$ & $\begin{array}{l}4.3 \text { Analisar } \\
\text { atribuindo }\end{array}$ & $\begin{array}{l}\text { C.c } \\
\text { Procedimental } \\
\text { de critérios }\end{array}$ \\
\hline \multirow{2}{*}{$\begin{array}{l}\text { H8 - Identificar etapas em processos de obtenção, } \\
\text { transformação, utilização ou reciclagem de } \\
\text { recursos naturais, energéticos ou matérias-primas, } \\
\text { considerando processos biológicos, químicos ou } \\
\text { físicos neles envolvidos }\end{array}$} & $\begin{array}{l}1.1 \text { Lembrar } \\
\text { reconhecendo }\end{array}$ & $\begin{array}{l}\text { C.b Procedimental } \\
\text { de técnicas }\end{array}$ \\
\hline & $\begin{array}{l}1.2 \text { Lembrar } \\
\text { lembrando }\end{array}$ & $\begin{array}{l}\text { B.c Conceitual } \\
\text { de estruturas }\end{array}$ \\
\hline $\begin{array}{l}\text { H9 - Compreender a importância dos ciclos } \\
\text { biogeoquímicos ou do fluxo energia para a vida, } \\
\text { ou da ação de agentes ou fenômenos que podem } \\
\text { causar alterações nesses processos }\end{array}$ & $\begin{array}{l}2.5 \text { Entender } \\
\text { inferindo }\end{array}$ & $\begin{array}{l}\text { B.c Conceitual de } \\
\text { estruturas }\end{array}$ \\
\hline \multirow{3}{*}{$\begin{array}{l}\text { H10 - Analisar perturbacões ambientais, } \\
\text { identificando fontes, transporte e(ou) destino } \\
\text { dos poluentes ou prevendo efeitos em sistemas } \\
\text { naturais, produtivos ou sociais }\end{array}$} & $\begin{array}{l}\text { 4.2 Analisar } \\
\text { organizando }\end{array}$ & \\
\hline & $\begin{array}{l}1.1 \text { Lembrar } \\
\text { reconhecendo }\end{array}$ & \\
\hline & $\begin{array}{l}2.5 \text { Entender } \\
\text { inferindo }\end{array}$ & \\
\hline \multirow{2}{*}{$\begin{array}{l}\text { H11 - Reconhecer benefícios, limitações e aspectos } \\
\text { éticos da biotecnologia, considerando estruturas } \\
\text { e processos biológicos envolvidos em produtos } \\
\text { biotecnológicos }\end{array}$} & $\begin{array}{l}1.1 \text { Lembrar } \\
\text { reconhecendo }\end{array}$ & $\begin{array}{l}\text { B.c Conceitual de } \\
\text { estruturas }\end{array}$ \\
\hline & $\begin{array}{l}1.2 \text { Lembrar } \\
\text { lembrando }\end{array}$ & $\begin{array}{l}\text { C.b Procedimental } \\
\text { de técnicas }\end{array}$ \\
\hline
\end{tabular}




\begin{tabular}{|c|c|c|}
\hline $\begin{array}{l}\text { H12 - Avaliar impactos em ambientes naturais } \\
\text { decorrentes de atividades sociais ou econômicas, } \\
\text { considerando interesses contraditórios }\end{array}$ & $\begin{array}{l}\text { 5.1 Avaliar } \\
\text { checando }\end{array}$ & $\begin{array}{l}\text { B.c Conceitual } \\
\text { de estruturas }\end{array}$ \\
\hline \multicolumn{3}{|l|}{ H13-16 - Relacionada à biologia } \\
\hline $\begin{array}{l}\text { H17 - Relacionar informações apresentadas em } \\
\text { diferentes formas de linguagem e representação } \\
\text { usadas nas ciências físicas, químicas ou biológicas, } \\
\text { como texto discursivo, gráficos, tabelas, relações } \\
\text { matemáticas ou linguagem simbólica }\end{array}$ & & $\begin{array}{l}\text { A.a Factual } \\
\text { de detalhes } \\
\text { e elementos } \\
\text { específicos }\end{array}$ \\
\hline $\begin{array}{l}\text { H18 - Relacionar propriedades físicas, químicas ou } \\
\text { biológicas de produtos, sistemas ou procedimentos } \\
\text { tecnológicos às finalidades a que se destinam }\end{array}$ & $\begin{array}{l}2.5 \text { Entender } \\
\text { inferindo }\end{array}$ & $\begin{array}{l}\text { B.a Conceitual } \\
\text { de classificações } \\
\text { e categorias }\end{array}$ \\
\hline $\begin{array}{l}\text { H19 - Avaliar métodos, processos ou procedimentos } \\
\text { das ciências naturais que contribuam para } \\
\text { diagnosticar ou solucionar problemas de ordem } \\
\text { social, econômica ou ambiental }\end{array}$ & $\begin{array}{l}2.5 \text { Avaliar } \\
\text { criticando }\end{array}$ & $\begin{array}{l}\text { B.c Conceitual } \\
\text { de estruturas }\end{array}$ \\
\hline \multicolumn{3}{|l|}{ H2O - Relacionada à física } \\
\hline \multirow{2}{*}{$\begin{array}{l}\text { H21 - Utilizar leis físicas e (ou) químicas para } \\
\text { interpretar processos naturais ou tecnológicos } \\
\text { inseridos no contexto da termodinâmica e(ou) } \\
\text { do eletromagnetismo }\end{array}$} & \multirow{2}{*}{$\begin{array}{l}\text { 3.1 Aplicar } \\
\text { executando } \\
\text { 2.1 Entender } \\
\text { interpretando }\end{array}$} & \multirow{2}{*}{$\begin{array}{l}\text { B.b Conceitual } \\
\text { de princípios e } \\
\text { generalizações } \\
\text { C.b Procedimental } \\
\text { de técnicas }\end{array}$} \\
\hline & & \\
\hline $\begin{array}{l}\text { H22 - Compreender fenômenos decorrentes } \\
\text { da interação entre a radiação e a matéria em } \\
\text { suas manifestações em processos naturais ou } \\
\text { tecnológicos, ou em suas implicações biológicas, } \\
\text { sociais, econômicas ou ambientais }\end{array}$ & $\begin{array}{l}2.5 \text { Entender } \\
\text { inferindo }\end{array}$ & $\begin{array}{l}\text { B.c Conceitual } \\
\text { de estruturas }\end{array}$ \\
\hline $\begin{array}{l}\text { H23 - Avaliar possibilidades de geração, uso ou } \\
\text { transformação de energia em ambientes específicos, } \\
\text { considerando implicações éticas, ambientais, sociais } \\
\text { e/ou econômicas }\end{array}$ & $\begin{array}{l}\text { 5.1 Avaliar } \\
\text { checando }\end{array}$ & $\begin{array}{l}\text { C.c Procedimental } \\
\text { de critérios }\end{array}$ \\
\hline \multirow{2}{*}{$\begin{array}{l}\text { H24 - Utilizar códigos e nomenclatura da química } \\
\text { para caracterizar materiais, substâncias ou } \\
\text { transformações químicas }\end{array}$} & $\begin{array}{l}\text { 3.1 Aplicar } \\
\text { executando }\end{array}$ & $\begin{array}{l}\text { A.a Factual de } \\
\text { terminologia }\end{array}$ \\
\hline & $\begin{array}{l}1.1 \text { Lembrar } \\
\text { reconhecendo }\end{array}$ & $\begin{array}{l}\text { A.b Factual } \\
\text { de detalhes } \\
\text { e elementos } \\
\text { específicos }\end{array}$ \\
\hline \multirow{3}{*}{$\begin{array}{l}\text { H25 - Caracterizar materiais ou substâncias, } \\
\text { identificando etapas, rendimentos ou implicaços } \\
\text { biológicas, sociais, econômicas ou ambientais de sua } \\
\text { obtenção ou produção }\end{array}$} & \multirow{3}{*}{$\begin{array}{l}1.1 \text { Lembrar } \\
\text { reconhecendo } \\
1.1 \text { Lembrar } \\
\text { reconhecendo }\end{array}$} & \multirow{3}{*}{$\begin{array}{l}\text { A.b Factual } \\
\text { de detalhes } \\
\text { e elementos } \\
\text { específicos } \\
\text { C.b Procedimental } \\
\text { de técnicas }\end{array}$} \\
\hline & & \\
\hline & & \\
\hline \multirow{2}{*}{$\begin{array}{l}\text { H26 - Avaliar implicações sociais, ambientais } \\
\text { e/ou econômicas na produção ou no consumo } \\
\text { de recursos energéticos ou minerais, identificando } \\
\text { transformações químicas ou de energia envolvidas } \\
\text { nesses processos }\end{array}$} & $\begin{array}{l}5.2 \text { Avaliar } \\
\text { criticando }\end{array}$ & \multirow[t]{2}{*}{$\begin{array}{l}\text { B.c Conceitual de } \\
\text { estruturas }\end{array}$} \\
\hline & $\begin{array}{l}1.2 \text { Lembrar } \\
\text { lembrando }\end{array}$ & \\
\hline \multirow{3}{*}{$\begin{array}{l}\text { H27 - Avaliar propostas de intervenção no meio } \\
\text { ambiente aplicando conhecimentos químicos, } \\
\text { observando riscos ou benefícios }\end{array}$} & $\begin{array}{l}\text { 5.1 Avaliar } \\
\text { checando }\end{array}$ & $\begin{array}{l}\text { C.c Procedimental } \\
\text { de critérios }\end{array}$ \\
\hline & $\begin{array}{l}\text { 3.1 Aplicar } \\
\text { executando }\end{array}$ & $\begin{array}{l}\text { B.c Conceitual } \\
\text { de estruturas }\end{array}$ \\
\hline & $\begin{array}{l}1.2 \text { Lembrar } \\
\text { lembrando }\end{array}$ & $\begin{array}{l}\text { B.c Conceitual } \\
\text { de estruturas }\end{array}$ \\
\hline
\end{tabular}

Fonte: Elaboração dos autores. 
As habilidades abrangem quase todas as categorias, à exceção de 6. Criar e D. Metacognitivo, nas duas dimensões. Como estão diretamente ligadas ao saber fazer em atividades específicas que perfazem uma ou várias competências, era de se esperar que estivessem ligadas aos aspectos procedimentais do conhecimento. Entretanto, a maioria dos objetivos (13) volta-se para o conhecimento Conceitual, enquanto as categorias Factual e Procedimental estão empatadas ( 9 objetivos cada). Embora não muito destacada, a valorização dos conceitos pode revelar uma preocupação com a aquisição de conhecimentos e suas inter-relações, como base para formar as competências.

TABELA 3 - Tabela taxonômica dos objetivos educacionais subjacentes às habilidades da matriz de referência das ciências da natureza e suas tecnologias do Enem 2009

\begin{tabular}{|c|c|c|c|c|c|c|}
\hline \multirow[b]{2}{*}{$\begin{array}{l}\text { Dimensão do } \\
\text { conhecimento }\end{array}$} & \multicolumn{6}{|c|}{ DIMENSÃO DO PROCESSO COGNITIVO } \\
\hline & 1. Lembrar & 2. Entender & 3. Aplicar & 4. Analisar & 5. Avaliar & 6. Criar \\
\hline $\begin{array}{l}\text { A. Conhecimento } \\
\text { factual }\end{array}$ & 3 & 3 & 1 & 2 & - & - \\
\hline $\begin{array}{l}\text { B. Conhecimento } \\
\text { conceitual }\end{array}$ & 4 & 4 & 2 & - & 3 & - \\
\hline $\begin{array}{l}\text { C. Conhecimento } \\
\text { procedimental }\end{array}$ & 3 & 2 & - & 1 & 3 & 1 \\
\hline $\begin{array}{l}\text { D. Conhecimento } \\
\text { metacognitivo }\end{array}$ & - & - & - & - & - & - \\
\hline
\end{tabular}

Fonte: Krathwohl (2002, p. 216).

No que tange aos processos cognitivos, surpreendentemente a ênfase está em 1. Lembrar (10 objetivos) e 2. Entender ( 9 objetivos). Era de se esperar que estivessem voltados para a aplicação de procedimentos ou conceitos, uma vez que estruturam as competências, como ferramentas úteis na resolução de novos problemas. O intuito parece ser o de preparar o aluno com conhecimentos e relações entre eles para que se desenvolvam as competências, mas, ao se focar em processos mnemônicos, mesmo que relacionados com conhecimentos conceituais, podem induzir ao simples lembrar de fórmulas, algoritmos e definições, em detrimento do entendimento das teorias, modelos e estruturas, perdendo a ideia de competências como "ações e operações que utilizamos para estabelecer relações com e entre objetos, situações, fenômenos e pessoas" (BRASIL, 2000a, p. 5), uma vez que estabelecer relações não é uma 
habilidade que se desenvolva pelo simples Lembrar, mas em categorias superiores, como Entender e Aplicar (MAYER, 2002, p. 227).

Assim, parece que o Enem objetiva que as escolas promovam um ensino mais voltado para o entendimento de problemas concretos, mas sem dar muita autonomia ao estudante para propor métodos e processos de intervenção no mundo, pois dá pouca atenção ao nível mais alto da taxonomia: 6. Criar. Formam-se, nessa perspectiva, indivíduos conformados com a realidade em que vivem e não capazes de modificá-la, aptos apenas para se encaixarem em diversas situações sociais, como novos empregos, novas culturas, sem no entanto tecerem sobre esses meios críticas e modificações conscientes. Questiona-se, ainda, se a redação é o único meio e se é eficaz para avaliar o processo criativo do indivíduo, uma vez que esse processo é complexo e multidimensional.

Sobre a avaliação, embora esteja inclusa na matriz, está direcionada ao conhecimento procedimental e aos conceitos que a embasam. Ficam geralmente na checagem (subcategoria 5.1) dos métodos e conceitos com teorias e estruturas maiores, porém não promovem a crítica (subcategoria 5.2) a esses modelos que seguem. Novamente, diminuem a autonomia do sujeito, que é formado apenas para seguir as leis, princípios e normas da sociedade e da realidade que lhe é imposta, mas incapaz de pensar ativamente sobre ela.

Outro ponto reforçador das ideias anteriores é a desconsideração do conhecimento metacognitivo. Não se valoriza a capacidade do aluno de encontrar maneiras de melhorar seu aprendizado, o que contraria a ideia de aprender a conhecer, e mantém o aluno alienado.

Com relação aos conteúdos curriculares, pauta-se no entender e lembrar de conceitos e procedimentos. A característica de aplicabilidade do conhecimento sugere que o ensino devia se pautar na resolução de problemas práticos, com a discussão de conceitos necessários para o seu entendimento. Logo, parece que os referenciais curriculares deveriam reduzir os conteúdos e seu aprofundamento de forma a atender a essa nova demanda, na qual a chave está na aplicabilidade de conhecimentos e não na aprendizagem deles per se. Sobre a metodologia pedagógica, esta deveria se pautar na aplicação dos conhecimentos em situações concretas. Assim, resta ao professor 
utilizá-las como ponto de partida para a construção de conceitos ou apenas para ilustrar a aplicabilidade dos mesmos.

Entretanto, tais mudanças podem não ocorrer, pois não se diferenciam em muito da prática docente atual. Em vez de estabelecer o aprendizado de forma a possibilitar ao aluno a resolução de problemas, pode-se acabar apenas na memorização de métodos e procedimentos. As habilidades, que já exibem tendência para a memorização, podem ter seu objetivo de entender transformado numa atividade mnemônica, pelo lembrar de fórmulas, descrição de conceitos, métodos algoritmos, entre outros. Logo, as competências formadas se restringirão apenas ao lembrar de receitas prontas. Corroboram-se, então, os resultados de Maceno et al. (2011, p. 157), que mostram que o Enem "contribuiria para que pouco fosse alterado nas práticas pedagógicas”, pois as mudanças previstas se aproximam, em muito, do método tradicional de ensino.

\section{CONSIDERAÇÕES FINAIS}

Os objetivos encontrados na análise das competências mostram que o Enem propõe um currículo centrado no ensino voltado à aplicação e entendimento de métodos e procedimentos usados no mundo atual, atribuindo-lhe um caráter mais prático, no sentido de que o conhecimento deve ser aplicado. As habilidades enfatizam o entender e o lembrar de conceitos necessários para serem aplicados nas situações-problema.

Não se privilegia a capacidade de criação, avaliação de conhecimentos e estruturas maiores, nem o conhecimento metacognitivo, implicando o desenvolvimento de indivíduos conformados com a realidade em que vivem e incapazes de alterá-la, contrariando o princípio de formação para cidadania que tanto defende.

Quanto aos conteúdos curriculares, eles deveriam se pautar na aprendizagem de procedimentos para resolver problemas cotidianos. Logo, deveriam ser repensados os referenciais curriculares para o ensino médio, que ainda se pautam em listas de conteúdos compartimentalizados e descontextualizados. Cabe ao professor trazer as situações vicárias para a sala de aula, tornando-as o ponto de partida para a aprendizagem. 
Entretanto, pela ênfase dada aos aspectos mnemônicos, implica pouca mudança na prática escolar, uma vez que se ingressaria na memorização de procedimentos e conhecimentos necessários para resolver um problema.

As pesquisas mostram que o Enem tem grande potencial para desenvolver mudanças nos currículos do ensino médio. Entretanto a análise de sua matriz referencial mostra que o exame está em descompasso com os demais documentos balizadores do sistema educacional, como a Lei de Diretrizes e Bases da Educação - LDB, os PCN, entre outros. Faz-se necessário o estudo das questões da prova e de seu método de aplicação para avaliar o cumprimento ou não dos paradigmas subjacentes à matriz. Deve-se repensar, no entanto, na sua função avaliativa e reestruturadora, uma vez que as inconsistências têm sido mostradas por pesquisas no campo educacional.

\section{REFERÊNCIAS}

BLOOM, B. S. (Ed.). Taxonomy of Educational Objectives: The classification of Educational Goals. Handbook I: Cognitive Domain. New York: Longmans, 1956.

BLOOM, B. S.; KRATHWOHL, D. R.; MASIA, B. B. Taxionomia de Objetivos Educacionais: 2. Domínio afetivo. Porto Alegre: Globo, 1974.

BRASIL. Instituto Nacional de Estudos e Pesquisas Educacionais Anísio Teixeira. Sobre o Enem, 2011. Disponível em: <http://portal.inep.gov.br/web/ enem/sobre-o-enem>. Acesso em: 9 set. 2011.

Ministério da Educação. Documento básico do Exame Nacional do Ensino Médio. Brasília: MEC/Inep, 2000a. Disponível em: <http://historico.enem.inep. gov.br/arquivos/Docbasico.pdf>. Acesso em: 17 jun. 2011.

Matriz de referência para o ENEM 2009. Brasília: MEC/INEP, 2009a. Disponível em: <http://portal.mec.gov.br/index.php?option=com_ docman\&task=doc_download\&gid=841\&Itemid=>. Acesso em: 17 jun. 2011.

Parâmetros Curriculares Nacionais para o Ensino Médio. Parte I. Bases Legais. Brasília: MEC/SEB, 2000b.

Parâmetros Curriculares Nacionais para o Ensino Médio. Parte III. Brasília: MEC/SEB, 2000b.

Portaria n. 109, de 27 de maio de 2009. Diário oficial da União. Seção 1, n. 100, p. 56-63, Brasília, 2009b. Disponível em: <http://www.enem.inep.gov. br/pdf/portaria_enem_2009_1.pdf>. Acesso em: 09 dez. 2009.

Portaria Ministerial n. 438, de 28 de maio de 1998. Institui o

Exame Nacional do Ensino Médio (Enem). Diário Oficial da União, Brasília, 
DF, 1 jun. 1998a. Seção 1, p. 5. Disponível em: <http://www.abmes.org.br/ legislacao/1998/Portarias.htm - 38k>. Acesso em: 15 nov. 2008.

. Secretaria de Educação Fundamental. Parâmetros Curriculares Nacionais: terceiro e quarto ciclos do ensino fundamental: introdução aos parâmetros curriculares nacionais. Brasília: MEC/SEF, 1998b.

DELORS, J. et al. Educação: um tesouro a descobrir. São Paulo: Cortez, Brasília: MEC, Unesco, 1998. Cap. 4.

DORNELES, R. M. P.; ALVES, G. L. Saúde ambiental segundo a percepção de graduandos de um curso de enfermagem à distância em Campo Grande, MS. Hygeia, n. 6, p. 128-142, dez. 2010.

FERRAZ, A. P. D. C. M.; BELHOT, R. V. Taxonomia de Bloom: revisão teórica e apresentação das adequações do instrumento para definição de objetivos instrucionais. Gestão \& Produção, São Carlos, v. 17, n. 2, p. 421-431, 2010.

FREITAS, A. H. et al. ENEM: um demonstrativo das mudanças socioeconômicas no perfil dos participantes. Meta: Avaliação, Rio de Janeiro, n. 1, p. 104-124, jan./abr. 2009.

GOMES, C. M. A.; BORGES, O. O Enem é uma avaliação educacional construtivista? Um estudo de validade de construto. Estudo em Avaliação Educacional, v. 20, n. 42, p. 73-87, jan./abr. 2009.

HORNBURG, N.; SILVA, R. Teorias sobre currículo: uma análise para compreensão e mudança. Revista de Divulgação Técnico-científica do ICPG, v. 3, n. 10, p. 61-66, jan./jun. 2007.

KRATHWOHL, D. R. A revision of bloom's taxonomy: an overview. Theory into Practice, v. 41, n. 4, p. 12-218, 2002.

LOPES, A. C. Políticas curriculares: continuidade ou mudança de rumos? Revista Brasileira de Educação, n. 6, p. 109-183, maio/ago. 2004.

LOPES, A. C.; LÓPEZ, S. B. A Performatividade nas políticas de currículo: o caso do ENEM. Educação em Revista [online], v. 26, n. 1, p. 89-110, 2010.

MACENO, N. G. et al. A Matriz de referência do Enem 2009 e o desafio de recriar o currículo de química na educação básica. Química Nova na Escola, v. 33, n. 3, p. 153-159, ago. 2011.

MARCELINO, L. V.; RECENA, M. C. P. Análise de questões do novo Enem segundo a taxonomia revisada de Bloom. In: REUNIÃO ANUAL DA SOCIEDADE BRASILEIRA DE QUÍMICA, 34, 2011, Florianópolis. Anais eletrônicos... Florianópolis: SBQ 2011a. Disponível em: <http://sec.sbq.org.br/ cdrom/34ra/resumos/T1345-1.pdf>. Acesso em: 12 set. 2011a.

Análise dos eixos cognitivos do novo Enem conforme a taxonomia revisada de Bloom. In: REUNIÃO ANUAL DA SOCIEDADE BRASILEIRA DE QUÍMICA, 34., 2011, Florianópolis. Anais eletrônicos... Florianópolis: SBQ 2011b. Disponível em: <http://sec.sbq.org.br/cdrom/34ra/resumos/T1345-2. pdf $>$. Acesso em: 12 set. 2011b.

MAYER, R. E. Rote versus meaningful learning. Theory into Practice, v. 41, n. 4, p. 226-232, 2002. 
MAYER, R. E.; ALEXANDER, P. A (Ed.). Handbook of research on learning and instruction. New York: Routledge, 2011.

MELLO, G. N. Afinal, o que é competência? Nova Escola, n. 160, mar. 2003.

MENDONÇA, J. L. A.; SILVA, R. M. G. Enem - uma proposta para selecionar, avaliar ou modelo curricular? O que dizem os professores de química do ensino médio. In: ENCONTRO NACIONAL DE ENSINO DE QUÍMICA, 15., 2010, Brasília. Anais... Brasília: UNB, 2010.

MINHOTO, M. A. Avaliação educacional no Brasil: crítica ao Exame Nacional do Ensino Médio. Dissertação (Mestrado em Educação) - PUC/SP, São Paulo, 2003.

Da disseminação da cultura de avaliação educacional: estudo sobre a institucionalização do Enem. Poiésis, Tubarão, n. 1, p. 67-85, jan./abr. 2008.

OLIVEIRA, M. Nota média do Enem sobe dez pontos em relação ao ano anterior, diz MEC. Jornal Nacional, São Paulo, 10 set. 2011. Disponível em: <http://g1.globo. com/vestibular-e-educacao/noticia/2011/09/nota-media-do-enem-sobe-dezpontos-em-relacao-ao-ano-passado-diz-mec.html>. Acesso em: 10 set. 2011.

PINTRICH, P. R. The Role of metacognitive knowledge in learning, teaching, and assessing. Theory into Practice, v. 41, n. 4, p. 219-225, fall 2002.

RAMALHO, B. L.; NÚÑEZ, I. B. Aprendendo com o Enem: reflexões para melhor se pensar o ensino e a aprendizagem das ciências naturais e da matemática. Brasília: Liber Livro, 2011.

SOUSA, S. M. Z. Possíveis impactos das políticas de avaliação no currículo escolar. Cadernos de Pesquisa, São Paulo, n.119, p.175-187, jul. 2003.

\section{LEONARDO VICTOR MARCELINO}

Licenciado em Química pela UFMS

leoviktor@hotmail.com

MARIA CELINA PIAZZA RECENA

Doutora em Ciências da Saúde pela Universidade

de Brasília. Professora e coordenadora do Programa

de Pós-Graduação em Ensino de Ciências da UFMS

morecena@yahoo.com.br 